\title{
Expulsion of Giant Intestinal Lipoma After Laparoscopic Roux-en-Y Gastric Bypass
}

\author{
B. Jakub Wilhelm, MD, Anai Hamasaki, MD, Leopoldo M. Baccaro, MD, Stanley Ogu, MD, \\ Artun Aksade, MD, FACS \\ Easton Hospital, Department of Surgery, Drexel University College of Medicine, Easton, Pennsylvania, USA (all authors).
}

\begin{abstract}
Introduction: Lipomas of the intestinal tract are rare, but they present as the third most common cause of intestinal neoplasms. Most intestinal lipomas are asymptomatic. However, they may present with bleeding, obstruction, intussusception, or abdominal pain. Spontaneous expulsion of an intestinal lipoma is extremely rare and has never been reported in the postoperative period.
\end{abstract}

Case Description: We present the case of a 53-year-old male patient who underwent laparoscopic roux-en-Y gastric bypass. On postoperative day 4 , the patient had a myocardial infarction and persistent abdominal discomfort. The spontaneous expulsion of an intestinal lipoma was observed on postoperative day 5 , after which the patient instantly felt relief. In this case report, we provide a comprehensive literature review of intestinal lipomas, with their complications and management.

Discussion: Only a few spontaneous expulsions of intestinal lipomas have been described in the literature. This is the first reported case of a spontaneous expulsion in the immediate postoperative period or after a myocardial infarction. Intestinal lipomas may cause a variety of complications, including bleeding, obstruction, and intussusception. The likelihood of complications increases with size. The criteria for resection remain controversial, and a variety of technical methods have been described. Spontaneous rectal expulsion of giant intestinal lipomas without surgical or endoscopic manipulation is possible.

Conclusion: Intestinal lipomas are rare and either are asymptomatic or present with unspecific symptoms. A consensus on the clinical management of intestinal lipomas has not been established. Besides open surgery, laparoscopic and endoscopic treatment options are emerging.

Key Words: Lipoma, Laparoscopy, Postoperative complications, Intestinal diseases, Abdominal pain.

Citation Wilhelm BJ, Hamasaki A, Baccaro LM, Ogu S, Aksade A. Expulsion of Giant Intestinal Lipoma After Laparoscopic Roux-en-Y Gastric Bypass CRSLS e2014.00185. DOI: 10.4293/JSLS.2014.00185.

Copyright (C) 2014 SLS This is an open-access article distributed under the terms of the Creative Commons Attribution-Noncommercial-ShareAlike 3.0 Unported license, which permits unrestricted noncommercial use, distribution, and reproduction in any medium, provided the original author and source are credited.

Address correspondence to: B. Jakub Wilhelm, MD, Easton Hospital, Department of Surgery, Drexel University College of Medicine, 250 South First Street, Easton, PA 18042, USA, Tel: (610) 250-4375, fax: +1 610250 4851, E-mail: jakubwilhelm@yahoo.com

\section{INTRODUCTION}

Lipomas are tumors deriving from the proliferation of mature adipocytes. Lipomas of the gastrointestinal tract grow in the submucosal plane in approximately $90 \%$ of the cases. Subserosal lipomas make up about $10 \%$ of the total. ${ }^{1,2}$ They can be found anywhere in the gastrointestinal tract. The most common location is the colon. ${ }^{3}$

Even though intestinal lipomas are rare, they represent the third most common benign intestinal neoplasm. Overall,
$5 \%$ of all gastrointestinal tract tumors are lipomas. ${ }^{4}$ Weinberg and Feldman ${ }^{5}$ conducted a large autopsy series of 60,000 cases and showed an incidence of $0.2 \%$.

Clinically, most gastrointestinal lipomas are asymptomatic (30\%). However, patients may present with a variety of symptoms, including abdominal pain, constipation, diarrhea, and rectal bleeding. Gastrointestinal lipomas can also cause obstruction or intussusception. ${ }^{4}$

Spontaneous expulsion of an intestinal lipoma per rectum is very rare, and only a few cases are described in the literature. ${ }^{4}$ 


\section{CASE DESCRIPTION}

A 53-year-old Caucasian man presented to our bariatric surgery service with morbid obesity. He failed all conservative methods for weight loss and inquired about surgical treatment options. His medical history included coronary artery disease, ischemic cardiomyopathy with a left ventricular ejection fraction of $25 \%$ to $30 \%$, type 2 diabetes mellitus with diabetic nephropathy, chronic obstructive pulmonary disease, obstructive sleep apnea, and chronic kidney disease. The patient had undergone quintuple coronary artery bypass graft surgery and the placement of an automated implantable cardioverter-defibrillator.

After preoperative evaluation, a laparoscopic roux-en-Y gastric bypass surgery was performed without complications. On postoperative day 1, upper gastrointestinal barium imaging confirmed the absence of an anastomotic leak.

The patient's postoperative recovery was unremarkable. He tolerated his diet and had regular bowel movements. On postoperative day 4, the patient developed shortness of breath. A cardiac workup was initiated, and electrocardiography showed ST-segment depressions in the inferior leads. The troponin I level was $6.0 \mathrm{ng} / \mathrm{mL}$, and the creatine kinase-MB level was $8.9 \mathrm{ng} / \mathrm{mL}$. The patient was diagnosed with a non-ST-segment elevation myocardial infarction. Treatment with clopidogrel and a heparin drip were started.

On postoperative day 5, the patient described a feeling of fullness, and abdominal distension was noticed during physical examination. Later that day, the patient expelled a $5.2 \times 3.6 \times 2.5 \mathrm{~cm}$ mass with his bowel movement, after which he felt instant relief. Histologic examination confirmed the presence of mature adipose tissue consistent with lipoma (Figure 1). After recovery from the non-STsegment elevation myocardial infarction, the patient was discharged home in stable condition.

\section{DISCUSSION}

Intestinal lipomas were first described by Bauer in 1757.4,6,7 The most common locations are the distal ileum, the ileocecal valve, and the ascending colon. ${ }^{8}$ These locations are followed in order by the transverse colon, descending colon, sigmoid colon, and rectum. Clinically, most intestinal lipomas are asymptomatic. ${ }^{4}$ Taylor and Wolf 9 showed that $46 \%$ of intestinal lipomas were incidentally found. Symptoms correlate with the size. Intestinal lipomas that are $<2 \mathrm{~cm}$ rarely cause any problems. ${ }^{4}$ On the other hand, lipomas $>2 \mathrm{~cm}$ in size are more likely to become symptomatic. ${ }^{10}$ Kitamura et al ${ }^{11}$ showed that $75 \%$ of patients with lipomas $>4 \mathrm{~cm}$ in size developed

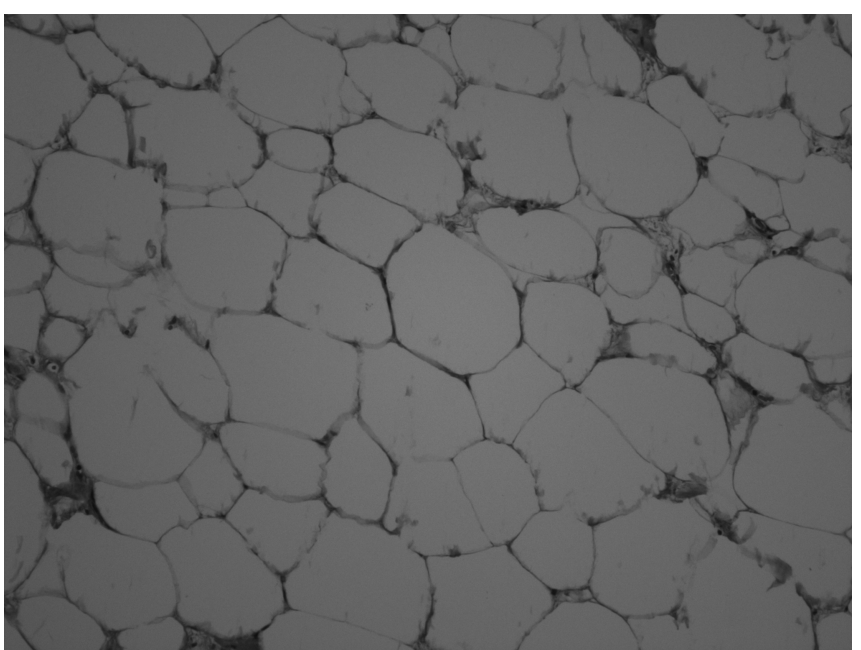

Figure 1. Histologic view of the giant intestinal lipoma.

symptoms. They can be as unspecific as abdominal pain, diarrhea, constipation, or rectal bleeding. ${ }^{10}$ The most common complication of intestinal lipomas is hemorrhage. ${ }^{12}$ Other complications include bowel obstruction, ${ }^{13}$ intussusception, 2,6,14 and invagination. ${ }^{15}$ Malignant transformation of intestinal lipomas has not been reported, ${ }^{10}$ and the risk is minimal. ${ }^{4}$ Pseudomalignant features can be observed during histopathologic examination and are attributed to intermittent episodes of ischemia. ${ }^{4,11}$

The diagnosis of intestinal lipomas can be established during surgery. Alternatively, they have been detected on various imaging modalities and diagnostic techniques such as computed tomography, barium enema, and colonoscopy. ${ }^{4}$ The success rate of preoperative diagnosis with modern imaging modalities such as computed tomography and magnetic resonance imaging is controversial. Recently, modalities such as computed tomographic colonographic examination (virtual colonoscopy) have been used to diagnose intestinal lipomas. ${ }^{14,16}$ However, investigators have reported that establishing a preoperative diagnosis was successful in only $62 \%$ of patients. ${ }^{4,17}$

The spontaneous rectal expulsion of intestinal lipomas is very rare. The first description of an expulsed lipoma was by Backenstoe in 1940. ${ }^{18}$ Since 1942, 19 cases have been reported. ${ }^{4}$ Spontaneous expulsion most commonly occurs with large pedunculated lipomas that have a thin pedicle. The mechanism of detachment remains unknown. ${ }^{4}$ To our knowledge, the postoperative occurrence of a spontaneous rectal expulsion of an intestinal lipoma has never been described, nor has there been a case reported in which a lipoma was passed during the immediate recovery phase of a myocardial infarction. 
The etiology of the spontaneous rectal expulsion of an intestinal lipoma in the postoperative period is unknown. Sympathetic stress during the perioperative period or during an acute myocardial infarction may lead to necrosis of a stalk in a large pedunculated lipoma and detach it from the intestinal wall. Subsequently, passing the lipoma with a normal bowel movement becomes possible. This mechanism can have therapeutic implications, as it may be possible to induce necrosis of the stalk endoscopically.

Controversy exists regarding the management of asymptomatic giant lipomas $(>4 \mathrm{~cm})$. The risk for developing intussusceptions from lipomas increases with their size. An analysis showed that the average size of lipomas that caused intussusceptions was $7 \mathrm{~cm}$ (range, $4-16 \mathrm{~cm}$ ). Thus, the authors suggested operative management before intussusception occurs in patients with asymptomatic lipomas $\geq 4 \mathrm{~cm}$ in size. $^{2}$ Besides the traditional open operative approach, newer modalities may include laparoscopic techniques. Colotomy and lipomatectomy should be attempted unless there is a concern for malignancy, in which case a more radical procedure may be chosen. Endoscopic methods to mobilize colonic lipomas are an alternative for lipomas that are $\leq 2$ $\mathrm{cm} .{ }^{4,11}$ Even in giant colonic lipomas that are asymptomatic and pedunculated, an attempt to endoscopically remove the tumor is warranted before surgically resecting it. Our case and the previously described case reports show that passing the tumor with a normal bowel movement is possible, even with giant lipomas.

\section{CONCLUSIONS}

An attempt to endoscopically remove an asymptomatic pedunculated colonic lipoma is warranted before surgically resecting it. Possibly, necrosis of the stalks could be induced endoscopically, followed by watchful waiting. However, small bowel lipomas that detach can lead to small bowel obstruction at the ileocecal valve. Our case and the previously described case reports show that passing the tumor with a normal bowel movement is possible, even with giant lipomas.

We thank Dr. Jeen Lee, Department of Pathology, for his support in providing his expertise. For editorial help, we thank Michael Schott.

\section{References:}

1. de Beer RA, Shinya H. Colonic lipomas. An endoscopic analysis. Gastrointest Endosc. 1975;22(2):90-91.

2. Paskauskas S, Latkauskas T, Valeikaite G, et al. Colonic intussusception caused by colonic lipoma: a case report. $\mathrm{Me}$ dicina (Kaunas). 2010;46(7):477-481.
3. Jeong HK, Cho SB, Seo TJ, et al. Autoamputation of a giant colonic lipoma. Gut Liver. 2011;5(3):380-382.

4. Kouritas VK, Baloyiannis I, Koukoulis G, Mamaloudis I, Zacharoulis D, Efthimiou M. Spontaneous expulsion from rectum: a rare presentation of intestinal lipomas. World J Emerg Surg. 2011;6:19.

5. Weinberg T, Feldman M Sr. Lipomas of the gastrointestinal tract. Am J Clin Pathol. 1955;25(3):272-281.

6. Mason R, Bristol JB, Petersen V, Lyburn ID. Education and imaging. Gastrointestinal: lipoma induced intussusception of the transverse colon. J Gastroenterol Hepatol. 2010;25(6):1177.

7. Ryan J, Martin JE, Pollock DJ. Fatty tumours of the large intestine: a clinicopathological review of 13 cases. Br J Surg. 1989;76(8):793-796.

8. Baskaran V, Patnaik PK, Seth AK, Dogra R, Chaudhry R. Intestinal lipoma: a rare cause of lower gastrointestinal haemorrhage. Trop Gastroenterol. 2003;24(4):208-210.

9. Taylor BA, Wolf BG. Colonic lipomas. Report of two unusual cases and review of the Mayo Clinic experience, 1976-1985. Dis Colon Rectum. 1987;30(11):888-893.

10. Bahadursingh AM, Robbins PL, Longo WE. Giant submucosal sigmoid colon lipoma. Am J Surg. 2003;186(1):81-82.

11. Kitamura K, Kitagawa S, Mori M, Haraguchi Y. Endoscopic correction of intussusception and removal of a colonic lipoma. Gastrointest Endosc. 1990;36(5):509-511.

12. Kaplan P. Submucous lipoma of the colon. Report of a case. Int Surg. 1971;56(2):113-117.

13. Ham JJ, Heiner JD, Gower LE, Litner JS. Abdominal pain caused by intestinal lipoma. West J Emerg Med. 2010;11(1):114.

14. Chiba T, Suzuki S, Sato M, et al. A case of a lipoma in the colon complicated by intussusception. Eur J Gastroenterol Hepatol. 2002;14(6):701-702.

15. Nussbaumer M, Hierholzer J. CT diagnosis of small intestine invagination due to small intestinal lipoma in an adult patient. Rofo. 2010;182(1):73-74.

16. Boehm G, Gschwendtner M. Lipoma: specific kind diagnosis in CT colonography. Rofo. 2008;180(6):565-566.

17. Buetow PC, Buck JL, Carr NJ, Pantongrag-Brown L, Ros PR, Cruess DF. Intussuscepted colonic lipomas: loss of fat attenuation on CT with pathologic correlation in 10 cases. Abdom Imaging. 1996;21(2):153-156.

18. Ginzburg L, Weingarten M, Fischer MG. Submucous lipoma of the colon. Ann Surg. 1958;148(5):767-772. 